\title{
Inactivation of a1-proteinase inhibitor by Candida albicans aspartic proteases favors the epithelial and endothelial cell colonization in the presence of neutrophil extracellular traps*
}

\author{
Mariusz Gogol', Dominika Ostrowska1, Kinga Klaga1, Oliwia Bochenska1, Natalia Wolak, \\ Wataru Aoki², Mitsuyoshi Ueda², Andrzej Kozik and Maria Rapala-Kozik, ${ }^{1,}$
}

1Department of Analytical Biochemistry, Faculty of Biochemistry, Biophysics and Biotechnology, Jagiellonian University in Kraków, Kraków, Poland; '2Division of Applied Life Sciences, Graduate School of Agriculture, Kyoto University, Sakyo-ku, Kyoto, Japan

Candida albicans, a causative agent of opportunistic fungal infections in immunocompromised patients, uses ten secreted aspartic proteases (SAPs) to deregulate the homeostasis of the host organism on many levels. One of these deregulation mechanisms involves a SAP-dependent disturbance of the control over proteolytic enzymes of the host by a system of dedicated proteinase inhibitors, with one important example being the neutrophil elastase and alpha1-proteinase inhibitor (A1PI). In this study, we found that soluble SAPs 1-4 and the cell membrane-anchored SAP9 efficiently cleaved A1PI, with the major cleavage points located at the C-terminal part of $\mathrm{A} 1 \mathrm{PI}$ in a close vicinity to the reactive-site loop that plays a critical role in the inhibition mechanism. Elastase is released by neutrophils to the environment during fungal infection through two major processes, a degranulation or formation of neutrophil extracellular traps (NET). Both, free and NET-embedded elastase forms, were found to be controlled by A1PI. A local acidosis, resulting from the neutrophil activity at the infection sites, favors A1PI degradation by SAPs. The deregulation of NET-connected elastase affected a NET-dependent damage of epithelial and endothelial cells, resulting in the increased susceptibility of these host cells to candidal colonization. Moreover, the SAP-catalyzed cleavage of A1PI was found to decrease its binding affinity to a proinflammatory cytokine, interleukin-8. The findings presented here suggest a novel strategy used by $C$. albicans for the colonization of host tissues and overcoming the host defense.

Key words: Candida albicans, aspartic proteases, a1-proteinase inhibitor, elastase, neutrophil extracellular traps, inflammation

Received: 31 July, 2015; revised: 17 September, 2015; accepted: 04 October, 2015; available on-line: 07 December, 2015

\section{INTRODUCTION}

Candida albicans is an opportunistic pathogen, harmlessly colonizing the human organism and detected in up to $70 \%$ of healthy individuals. However, weakening the host immune system and the frequent use of antibiotics and steroids increase a risk of fungal infections (Bakare et al., 2003). In severe conditions, the superficial infections may further develop into life-threatening disseminated candidiasis with a high $(30-50 \%)$ mortality rate (Santos \& Braga-Silva, 2013). To invade host mucosal surfaces, $C$. albicans uses many virulence factors that enable the fungal cells to survive in a diverse physiological niches such as oropharynx or urogenital or gastrointestinal tracts (Calderone \& Fonzi, 2001; Mech et al., 2013). Among them, a crucial role is played by a family of secreted aspartic proteases (SAPs) whose expression differs between unicellular (yeast-like) and filamentous morphological forms of $C$. albicans (Naglik et al., 2003). A majority of SAPs are released to the surrounding environment (SAP1-SAP8) but SAP9 and SAP10 are attached to the cell wall/membrane through a glycosylphosphatidylinositol (GPI) anchor (Hube \& Naglik, 2001). These proteases exhibit broad substrate specificities, promoting infection development by the degradation of host proteins that function in tissue barriers and in immune defense (Pietrella et al., 2010; Rapala-Kozik et al., 2015; Kozik et al., 2015).

Neutrophils are principal mediators of innate immunity against microbial invaders. Apart from the phagocytosis and extracellular degranulation, they are able to combat microbes by formation of neutrophil extracellular traps (NETs). These web-like structures are built of a decondensed chromatin and numerous proteins, mainly originating from neutrophil granules, with antimicrobial properties (Urban et al., 2009). However, the NET release poses a threat to the tissue, associated with the proteolytic activity of neutrophil proteases (such as elastase and proteinase 3 ) and the oxidative properties of myeloperoxidase, the enzymes that are important structural elements of NETs. Elastase (NE) plays pivotal roles in the pathogenesis of pulmonary fibrosis and in the development and progression of acute respiratory distress syndrome (Takemasa et al., 2012; Tagami et al., 2014). Initially, NE is stored in the azurophilic granules of neutrophils, but during NET formation it processes core histones to promote chromatin decondensation and contributes to NET-dependent tissue damage after NET release into the surrounding environment (Papayannopoulos et al., 2011). Therefore, processes such as the neutrophil migration, initiation of the trap formation and elastase activity must be strictly controlled. Regulation may occur by means of $\alpha 1$-protease inhibi-

e-mail: maria.rapala-kozik@uj.edu.pl

*The results were presented at the 6th International Weigl Conference on Microbiology, Gdańsk, Poland (8-10 July, 2015).

Abbreviations: A1PI, a1-proteinase inhibitor; dA1PI, degraded A1PI; NE, neutrophil elastase; SAPs, secreted aspartic proteases; NETs, neutrophil extracellular traps; IL-8, interleukin 8; HPLC, high performance liquid chromatography; LC-MS/MS, liquid chromatography-coupled tandem mass spectrometry; SDS-PAGE, sodium dodecyl sulfate polyacrylamide gel electrophoresis; PMA, phorbol 12-myristate 13-acetate 
tor (A1PI). This member of the serpin (serine protease inhibitor) family, synthesized mainly by hepatocytes, is the main NE inhibitor that circulates in the bloodstream from which it diffuses into the lower respiratory tract, providing $>90 \%$ anti-elastase protection there (Greene et al., 2003). It is known that in addition to its inhibitory properties, A1PI also has a regulatory capacity in the inflammatory processes, weakening both neutrophil chemotaxis due to IL-8 binding (Bergin et al., 2010) and the production of free radicals, probably due to some ROS-scavenging properties (Taggart et al., 2000).

Bacteria that cause pulmonary infections, such as Psendomonas aeruginosa, Haemophilus influenzae and Staphylococcus aureus, express enzymes capable of inactivating A1PI, thus contributing to an impaired balance between $\mathrm{NE}$ and A1PI within the airways that can lead to tissue destruction and progression of the disease (Suter \& Chevallier, 1991). It was also suggested that the common fungal pathogen - C. albicans yeast - can affect the integrity and function of A1PI (Kaminishi, 1999). Therefore, aim of the present study was to analyze the cleavage of A1PI by SAPs and the effects of this proteolytic processing on the NET-embedded NE activity and NET-dependent damage of epithelial and endothelial cells, with a possible further influence on the propagation of fungal infection.

\section{MATERIALS AND METHODS}

Cell culturing. Human microvascular endothelial cells (HMEC-1) and human epithelial carcinoma cell line A431 were obtained from ATCC. HMEC-1 were cultured in MCDB 131 medium (Sigma, St. Louis, MO, USA) and A431 cells in DMEM medium (Thermo Scientific, HyClone, Logan, USA). Media were supplemented with $10 \%$ fetal bovine serum (FBS), 100 units/ml penicillin-streptomycin and $2 \mathrm{mM}$ glutamine, and MCDB 131 medium was additionally supplemented with $1 \mu \mathrm{g} /$ $\mathrm{ml}$ hydrocortisone and $10 \mathrm{ng} / \mathrm{ml}$ EGF. The cells were cultured in $5 \% \mathrm{CO}_{2}$ atmosphere at $37^{\circ} \mathrm{C}$.

Yeast culturing. C. albicans strain ATCC 10231 was grown under conditions that favored either yeast-like or hyphal morphology. Yeast-like forms were cultured at $30^{\circ} \mathrm{C}$ in YPD medium (Serva, Heidelberg, Germany) buffered with $50 \mathrm{mM}$ sodium-phosphate $\mathrm{pH} 6.5$ and containing $0.2 \%$ yeast extract, $0.2 \%$ peptone and $2 \%$ glucose. In order to induce hyphae formation, C. albicans was grown in RPMI medium (Sigma) at $37^{\circ} \mathrm{C}$. After $24 \mathrm{~h}$, the yeast cells were harvested by centrifugation $(3000 \times g, 10 \mathrm{~min})$ and SAP-containing supernatants were ten-fold concentrated using an Amicon ultrafiltration chamber (Danvers, MA) equipped with the ultrafiltration membrane with $10-\mathrm{kDa}$ exclusion limit.

Isolation of neutrophils from human peripheral blood. Human neutrophils were isolated according to a previously described method (Rapala-Kozik et al., 2015) using EDTA-treated whole-blood samples collected from healthy donors. Neutrophil-containing fractions were separated by Pancoll gradient (PAN-Biotech, Aidenbach, Germany) and treated with 1\% solution of polyvinyl alcohol (Sigma) in PBS. Contaminating erythrocytes were removed by hypotonic lysis, and neutrophils were resuspended in RPMI 1640 medium (phenol red-free). This preparation method yields a $>95 \%$ pure population of neutrophils.

NET release and isolation. Neutrophils $\left(1 \times 10^{6}\right.$ cells in $800 \mu \mathrm{l} \mathrm{RPMI})$ were seeded for $30 \mathrm{~min}$ at $37^{\circ} \mathrm{C}$ and $5 \% \mathrm{CO}_{2}$, on a 12 -well microplate (Greiner BioOne, Germany), previously coated with $0.01 \%$ poly-L-ly- sine. Cells were then stimulated to produce NETs with $50 \mathrm{nM}$ phorbol 12-myristate 13-acetate (PMA) (Sigma) for 3 hours at $37^{\circ} \mathrm{C}$ and $5 \% \mathrm{CO}_{2}$. After gentle triple washing of each well with $1 \mathrm{ml}$ of PBS, NETs were treated with $400 \mu \mathrm{l}$ of Micrococcal nuclease (MNase, $1 \mathrm{U} / \mathrm{ml}$ ) (Roche, Penzberg, Germany) for $20 \mathrm{~min}$ at $37^{\circ} \mathrm{C}$. The reaction was stopped with EDTA. The supernatant was collected and centrifuged for $5 \mathrm{~min}$ at $300 \times g$ at $4^{\circ} \mathrm{C}$ to remove the cell debris. The NET-rich supernatants were then analyzed for their DNA fragmentation using agarose gel electrophoresis. For protein determination in the samples, Micro-BCA protein assay reagent kit (Pierce, Germany) was used and DNA content was quantified using staining with SytoxGreen (Invitrogen Life Technologies, Germany) and fluorescence measurement (465/525nm) using a Biotek Synergy H1 microplate reader.

Degradation of A1PI in SAP-containing supernatants. A1PI $(1 \mu g / 30 \mu l)$ (Preparatis, Poland) was incubated with cell-free supernatants containing $5 \mu \mathrm{g} /$ $\mathrm{ml}$ of secreted proteins at $\mathrm{pH}$ in the range of 4-7 (50 $\mathrm{mM}$ citrate $\mathrm{pH} 4-6$ or $50 \mathrm{mM}$ phosphate buffer $\mathrm{pH} 7$ ) for $20 \mathrm{~h}$ at $37^{\circ} \mathrm{C}$, in the presence of $10 \mu \mathrm{M}$ pepstatin A or without this aspartic-protease inhibitor. The degradation of A1PI was examined using a colorimetric assay that monitors a decrease of inhibitory capacity against trypsin (Sigma). The reaction was conducted in $100 \mathrm{mM}$ Tris- $\mathrm{HCl} \mathrm{pH} 8$, at an enzyme : inhibitor molar ratio of $1: 1$ at $37^{\circ} \mathrm{C}$. Trypsin activity was detected using $N-\alpha-$ benzoyl-L-arginine 4-nitroanilide hydrochloride (Sigma) as the substrate, and determined after $30 \mathrm{~min}$ of incubation by absorbance measurement at $410 \mathrm{~nm}$.

Degradation of A1PI and IL-8 by individual purified SAPs. Ten SAPs were overproduced in Pichia pastoris GS115 (Invitrogen, USA) as was described previously (Aoki et al., 2011). A1PI and IL-8 were incubated with all SAPs at an enzyme: substrate molar ratio of 1:20 in $50 \mathrm{mM}$ citrate buffer, $\mathrm{pH} 5$ and 6 , at $37^{\circ} \mathrm{C}$ for $20 \mathrm{~h}$. The reaction was stopped by addition of pepstatin $\mathrm{A}$ at a final concentration of $10 \mu \mathrm{M}$. Products of degradation were separated and identified by SDS-PAGE in the Laemmli system (Laemmli, 1970) on a 12\% gel, with band visualization by silver staining (Blum et al., 1987).

Analysis of the inhibitory properties of native and SAP-treated A1PI towards native or NET-associated neutrophil elastase. The analysis of inhibitory properties of native and SAP degraded A1PI (dA1PI) were performed in $100 \mathrm{mM}$ Tris- $\mathrm{HCl} \mathrm{pH} 8.0$ for $30 \mathrm{~min}$ at $37^{\circ} \mathrm{C}$ in a 96-well microtiter plate. Both forms of the inhibitor were incubated with native or NET-associated neutrophil elastase at an enzyme : inhibitor molar ratio of $0: 1,0.25: 1,0.5: 1,1: 1,2: 1$ and $3: 1$. The amount of NET-associated NE in total pool of isolated NET-associated protein was estimated according to data presented by Urban et al. (2009). The residual enzyme activity was determined using a chromogenic substrate, MeOSuc-AlaAla-Pro-Val-pNA (Sigma). Progress of the reaction was measured spectrophotometrically at $410 \mathrm{~nm}$.

Mass spectrometry analysis of A1PI degradation products generated by SAP-catalyzed proteolysis. The products obtained after degradation of A1PI by those SAPs which exhibited the highest hydrolytic activity toward this inhibitor were analyzed by liquid chromatography (LC)-coupled tandem mass spectrometry (MS/MS). The low molecular mass degradation products were analyzed directly using the LC-MS/MS system. After SDS-PAGE, the bands of the main degradation products were in-gel digested with trypsin. Briefly, after the visualization of the protein fragments with the colloi- 
dal Coomassie Brilliant Blue dye, the excised pieces were washed twice with $50 \mathrm{mM}\left(\mathrm{NH}_{4}\right) \mathrm{HCO}_{3}$ in $25 \%$ and $50 \%$ acetonitrile (ACN, high-performance liquid chromatography (HPLC)-gradient grade, Merck, Darmstadt, Germany) to remove the dye from the gel. After reduction with $10 \mathrm{mM}$ dithiotreitol (DTT) for $60 \mathrm{~min}$ at $37^{\circ} \mathrm{C}$, samples were alkylated with $55 \mathrm{mM}$ iodoacetamide for 2 hours in the dark and then washed with $100 \mathrm{mM}\left(\mathrm{NH}_{4}\right) \mathrm{HCO}_{3}$. After dehydration with ACN, samples were dried and subsequently re-swelled with a digestion buffer, containing $12.5 \mathrm{ng} / \mu \mathrm{l}$ of the sequencing-grade modified trypsin (Promega, Madison, WI, USA), $50 \mathrm{mM}\left(\mathrm{NH}_{4}\right) \mathrm{HCO}_{3}$ and $4 \mathrm{mM} \mathrm{CaCl}_{2}$. The gel pieces were incubated overnight at $37^{\circ} \mathrm{C}$. The extractions of acidic and basic peptides were conducted by addition of $50 \mathrm{mM}\left(\mathrm{NH}_{4}\right) \mathrm{HCO}_{3}$ and $5 \%$ formic acid in 50\% ACN, respectively. Combined supernatants were diluted with water and subjected to the LC-MS/MS analysis using ultra-high-performance liquid chromatography (UHPLC) Dionex Ultimate 3000 system (Thermo-Scientific, Woltham, MA, USA) coupled to HTCultra ETDII ion-trap mass spectrometer equipped with electrospray (ESI) ion source and electron transfer dissociation (ETD II) fragmentation module (Bruker, Bremen, Germany). The A1PI fragments were separated on Accucore C-18 column $(2.6 \mu \mathrm{m}, 2.1 \times 100 \mathrm{~mm}$, ThermoScientific) in a binary linear gradient formed between solvent A (0.1\% formic acid (Sigma)) and solvent $\mathrm{B}(0.1 \%$ formic acid in $80 \% \mathrm{ACN})$, from 10 to $55 \%$ of $\mathrm{B}$ in $38 \mathrm{~min}$, at a flow rate of $0.2 \mathrm{ml} / \mathrm{min}$.

The mass spectrometry measurements were performed with the following instrument setup: a positive ion mode, capillary voltage of $3.5 \mathrm{kV}$, the nebulizing gas (nitrogen) pressure of 40 psi, drying gas (nitrogen) flow of $12 \mathrm{l}$ / min and the dry gas temperature of $350^{\circ} \mathrm{C}$. Spectra were acquired in MS/MS mode in the range of $100-3000 \mathrm{~m} / \mathrm{z}$. with CID (collision-induced dissociation) and ETD ion fragmentation, and analyzed using Data Analysis'TM 4.0 and BiotoolsTM 3.2 software (Bruker, Germany). The identification of peptide sequences was performed by submission of the data to an in-house Mascot server ver. 2.3.0 (Matrix Science, UK) and based on searching against Swiss-Prot database.

ELISA method for the detection of the IL-8 binding by native and degraded A1PI. Native A1PI and its degraded forms obtained by treatment with representative SAPs (dA1PI) were used to detect their binding capacity to IL-8 (Novoprotein Scientific). The formation of the A1PI- and dA1PI-IL-8 complex was analyzed by a sandwich ELISA method. The mixtures, containing constant amount of IL-8 and native or degraded A1PI at a molar ratio of $0.05: 1,0.1: 1,1: 1,2: 1$ were incubated at room temperature for $1 \mathrm{~h}$. The samples were then added to 96-well microtiter plates coated with anti-IL-8 antibody and incubated for $1.5 \mathrm{~h}$ at room temperature. The amount of free IL-8 versus A1PI/dA1PI-bound IL-8 was determined using HUMAN IL-8 ELISA KIT II (BD OptEIA) according to the supplier's instructions.

Treatment of human cells with NETs and the viability tests. HMEC- 1 and A431 cells were seeded on 96-well plates $\left(2 \times 10^{4}\right.$ cells/well in $200 \mu \mathrm{l}$ medium $)$ and cultured to $90 \%$ of confluency. The cells were washed with PBS, and then the NET suspension with total protein concentrations of $0,10,20,30 \mu \mathrm{g} / \mathrm{ml}$ in the medium were added. After $22 \mathrm{~h}$ of incubation at $37^{\circ} \mathrm{C}$, the wells were washed with PBS. Viability of the cells was estimated with the MT'T assay (Sigma).

To determine the influence of A1PI or dA1PI inhibition on the activity of NE-accompanying NETs, the NET samples $(10 \mu \mathrm{g} / \mathrm{ml})$ were first incubated with A1PI or dA1PI for $1 \mathrm{~h}$ as above, and then applied to the cells. The cells treated with pure medium were used as a control. Special references for possible influence of SAPs used for A1PI treatment at corresponding concentrations were applied instead of NET samples during the determination of cell viability.

Treatment of $C$. albicans with NETs and the yeast survival tests. C. albicans cells were harvested at the stationary phase by centrifugation at $1500 \times g$ for 10 min, then were washed twice with PBS and diluted to a concentration of $5 \times 10^{4}$ cells $/ \mathrm{ml}$ in PBS. In order to evaluate the impact of NETs on the viability of $C$. albicans cells, the yeast cell suspensions (200 $\mu \mathrm{l} /$ well $)$ were incubated with NETs as described above at 0-30 $\mu \mathrm{g} /$ $\mathrm{ml}$ concentration of NET protein components, and at various time intervals. After incubation, the cell viability analysis was performed using MT'T test, as well as the number of viable Candida cells was determined by plating the serial dilutions of cell suspensions on Sabouraud dextrose agar plates. The CFU (colony forming units) were counted after $24 \mathrm{~h}$ of incubation at $30^{\circ} \mathrm{C}$.

Analysis of NET-dependent human cell destruction effects on $\boldsymbol{C}$. albicans propagation. To analyze the effect of human cell destruction by NETs on $C$. albicans propagation two models of co-cultures were used.

A one-step co-culture. The human cell monolayers covered with $C$. albicans cells $\left(5 \times 10^{4}\right.$ cells/well of 96-well microplate) were treated with NETs $(0,10,20,30 \mu \mathrm{g} /$ $\mathrm{ml}$ ) for $2-4 \mathrm{~h}$ at $37^{\circ} \mathrm{C}$. After incubation, the supernatants were removed and the cells were gently washed with PBS. Yeasts attached to the human cell monolayers were scraped gently with pipet tips and washed with $200 \mu \mathrm{l}$ of distilled water. The resulting suspensions were diluted 10-fold, spread on Sabouraud agar plates and handled further as described above.

A two-step co-culture. The human cell monolayers were first treated with NET samples $(0,10,20,30 \mu \mathrm{g} /$ $\mathrm{ml}$ of protein concentration) for $2-4 \mathrm{~h}$ at $37^{\circ} \mathrm{C}$. Then the supernatant was removed and the stability of monolayer was checked by phase contrast microscopy before addition of $C$. albicans cells $\left(5 \times 10^{4}\right.$ cells/well of 96 -well plate) for the next $2 \mathrm{~h}$ of incubation under the same conditions. The $C$. albicans cells attached to the human cell monolayer were quantified as described above.

Statistical analysis. The unpaired one-tailed Student's $t$-test with a Bonferroni correction where necessary was used. A $p$ value $<0.05$ was considered significant.

\section{RESULTS}

\section{Several aspartic proteases of C. albicans efficiently degrade A1PI}

In order to demonstrate a potential ability of aspartic proteases secreted by $C$. albicans to degrade A1PI at the infection foci, A1PI samples were treated with SAP-containing supernatants from $C$. albicans cultures propagated under conditions favoring either yeast-like (YPD supplemented with $0.2 \% \mathrm{BSA}$ ) or hyphal (RPMI) morphology of the fungus. Influence of the degradation process on the inhibitory properties of A1PI towards trypsin was tested (Fig. 1A). We found that a more efficient inactivation of A1PI occurred in the presence of supernatants obtained from conditions that favor yeast-like morphology, at the $\mathrm{pH}$ range from 4 to 6 . Using pepstatin $\mathrm{A}$, a selective aspartic protease inhibitor, we confirmed SAP involvement in the presented A1PI inactivation. 

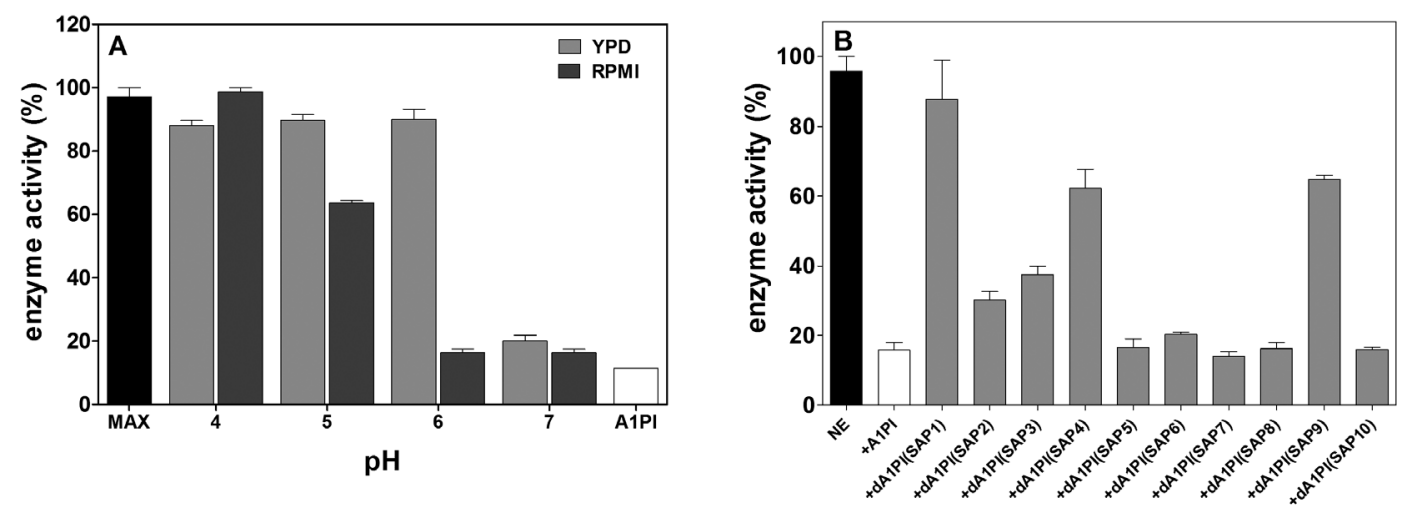

Figure 1. Changes of A1PI inhibitory properties upon treatment with C. albicans aspartic proteases.

A1PI was degraded (dA1PI) at different $\mathrm{pH}$ by cell-free supernatants, containing SAPs produced by $C$. albicans cells, cultured in YPD or RPMI medium (A) or treated by purified SAPs, overexpressed in P. pastoris (B). The reaction was monitored for residual A1PI inhibitory capacity against trypsin at an enzyme:inhibitor molar ratio of 1:1, using Na-benzoyl-L-arginine 4-nitroanilide hydrochloride as substrate. The activity of uninhibited trypsin under the same experimental conditions was taken as $100 \%$.

To select among all SAPs for those enzymes that mainly participate in the process, A1PI samples were treated with purified individual SAPs at enzyme:substrate ratios of $1: 20$ for $20 \mathrm{~h}$ at $37^{\circ} \mathrm{C}$. The retained inhibitory capacity of degraded A1PI, analyzed by using trypsin as the test enzyme, pointed out to SAP1, SAP2, SAP3, SAP4 and SAP9 as proteases leading to the loss of A1PI inhibitory properties (Fig. 1B).

The SDS-PAGE analysis (Fig. 2, left panel) correlated the above enzymatic activity tests with visible cleavage of A1PI molecule by the SAP representatives mentioned above. At a more acidic $\mathrm{pH}$, SAPs produced by both morphological forms of $C$. albicans were able to cleave A1PI. However, at a broader $\mathrm{pH}$ range, A1PI was cleaved by SAPs that are mainly associated with the yeast-like form of C. albicans (SAP1, SAP2, SAP3 and SAP9). The last one, SAP9, is also expressed by the hyphal form, but is rarely secreted into the medium and has a predominant membrane localization (Naglik et al., 2003). The hyphae-associated SAP4 was comparably effective in A1PI degradation at $\mathrm{pH} 5$, confirming the results presented for A1PI treated with the SAP-containing supernatants.

To localize the points of SAP-dependent cleavage within A1PI molecule, the amino acid sequences of the main products were identified by in-gel digestion of SDS-PAGE-separated bands with trypsin, followed by LC-MS/MS analysis. This analysis revealed that the cleavage of A1PI was mainly limited to the hydrolysis of

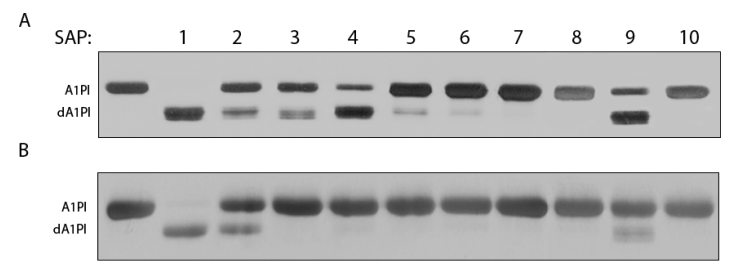

Figure 2. Identification of the cleavage products of A1PI processing by Candida aspartic proteases.

Left panel: SDS-PAGE analysis of A1PI degradation products generated during $\mathrm{A} 1 \mathrm{PI}$ contact with individual SAPs at an enzyme : substrate molar ratio of 1:20 in $50 \mathrm{mM}$ citrate buffer, $\mathrm{pH} 5(\mathbf{A})$ and 6 (B) at $37^{\circ} \mathrm{C}$ for $20 \mathrm{~h}$. A1PI and its degradation product (dA1PI) were visualized by silver staining of SDS-PAGE gels. Right panel: The mass-spectrometry identification of A1PI degradation products with indication of major cleavage points by NE (black arrow) and SAP9 (gray arrows). The sequence underlined represents the known cleavage region for bacterial proteases.
K343-G344 bond, resulting in a formation of a stable product (dA1PI) with the sequence shortened by 51 amino acid residues in comparison to the native A1PI form (Fig. 2, right panel). The shorter peptide was further degraded into smaller variants, without any effect on the dA1PI properties.

\section{SAP-degraded A1PI changes its inhibitory activity towards neutrophil elastase, present in NET structures, and looses the ability to bind IL-8}

The main target for homeostatic function of A1PI in human organism is $\mathrm{NE}$ that during microbial infection can be spread as the NET constituent at the sites of neutrophil contact with microbes. First, we tested if NE localized to NET structures during their isolation is still active and possibly available for and inhibited by A1PI (Fig. 3A). The comparable results of inhibition obtained for native and NET-associated NE corroborated such model. Moreover, the treatment of NET-embedded NE with A1PI degraded by the most potent SAPs (dA1PI) led to the partial restoration of NE activity as compared to treatment with native A1PI (Fig. 3B).

The intensification of NET production at sites of bacterial or fungal infection occurred as a results of the action of additional stimuli, such as IL- 8 which is produced by incoming or surrounding cells. However, the availability of IL-8 can be modulated by its binding to A1PI. On the other hand, a degradation of IL- 8 by any SAP

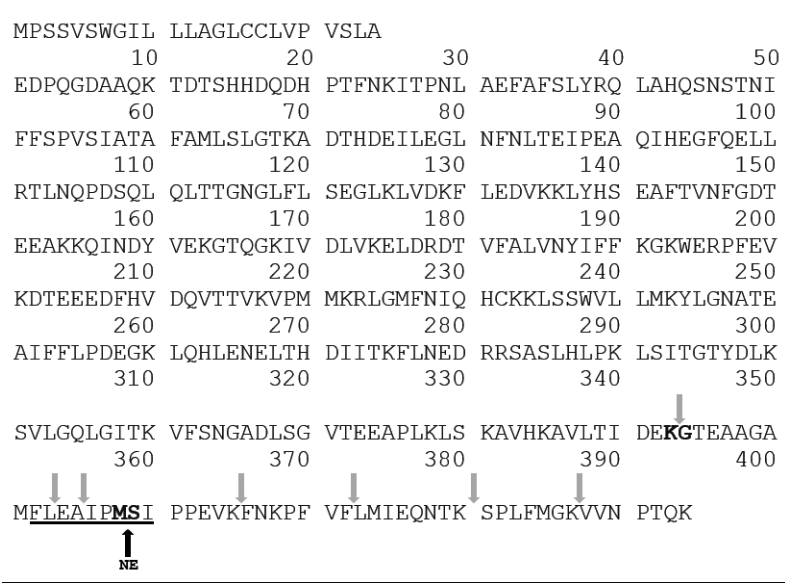



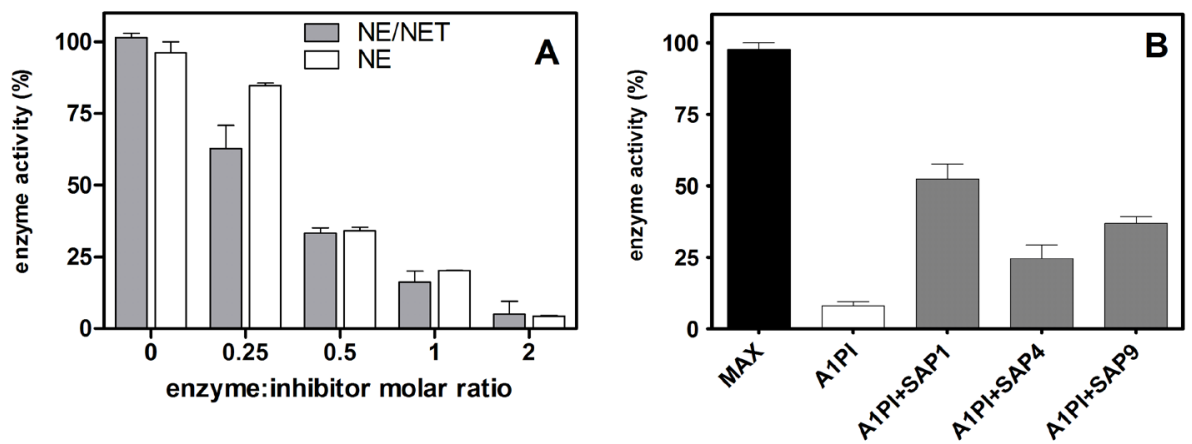

Figure 3. Influence of SAP-catalyzed A1PI degradation on its inhibitory properties against elastase, embedded in NET structures. Inhibition of native (NE) and NET-associated elastase (NE/NET) by A1PI was compared using various enzyme:inhibitor molar ratios (A). The residual activity of NE was measured with MeOSuc-Ala-Ala-Pro-Val-pNA as substrate. Effect of A1PI degradation by selected SAPs on the inhibitory capacity against NE/NET was carried out under the same conditions using an enzyme:inhibitor molar ratio of 1:1 (B).

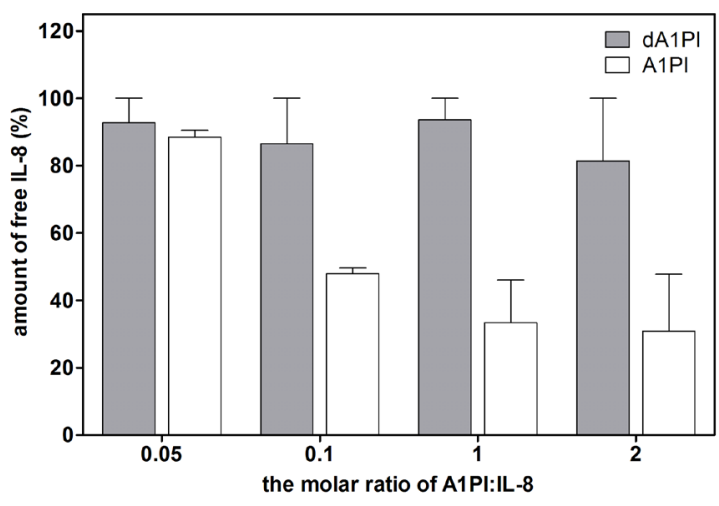

Figure 4. IL-8 binding by native (A1PI) and SAP-degraded (dA1PI) elastase inhibitor.

Formation of the complexes of A1PI/dA1PI with IL-8 was detected using HUMAN IL-8 ELISA Kit II at a constant amount of IL-8 and varied $\mathrm{A} 1 \mathrm{PI} / \mathrm{dA} 1 \mathrm{PI}$ ratio. at different incubation time, $\mathrm{pH}$ and IL-8:SAP ratio was not observed (data not presented). To test the influence of A1PI degradation on A1PI ability to form a complex with IL-8, we used an ELISA method in which the cytokine unbound to A1PI was detected. The IL-8 binding by A1PI that prevents IL8 detection at the experimental conditions of ELISA test, was observed (Fig. 4). However, the degraded A1PI (dA1PI) blocked efficiently the complex formation with IL-8, whose molecules were still detected in solution during the experiments.

\section{Human cell destruction by NETs can be influenced by A1PI and modulated by C. albicans SAPs}

A number of studies had shown that an excessive production of NETs can lead to cell and tissue destruction (Saffarzadeh et al., 2012), for which the regulation of elastase activity may be crucial. To address this problem, we chose two types of human cell lines, epithelial (A431) and endothelial (HMEC-1), that were treated with isolated NETs and, thereafter, the cell viability was measured using the MTT test. To eliminate possible side
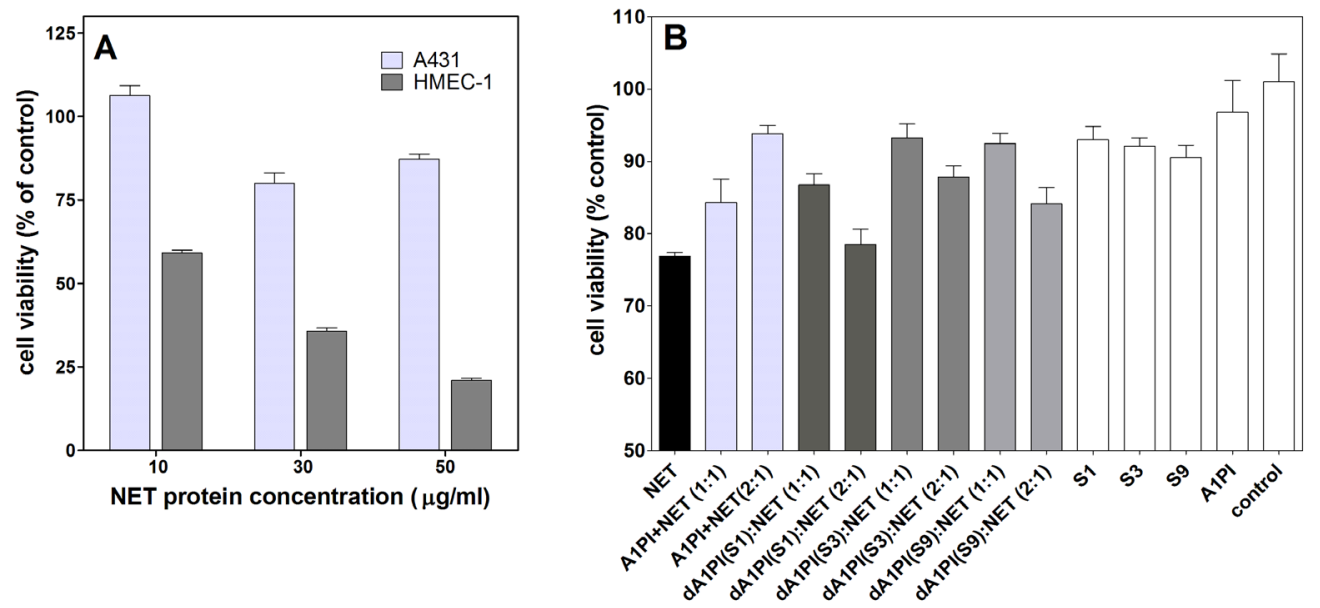

Figure 5. NET toxicity against human cells and its changes upon cell treatment with A1PI.

HMEC-1 and A431 cell monolayers were treated with suspension of NETs at different total protein concentrations (0-50 $\mu \mathrm{g} / \mathrm{ml})$ for $22 \mathrm{~h}$. The viability of the cells was measured by the MTT assay and relatively expressed to non-treated cells $(\mathbf{A})$. The impact of $A 1 P I$ and $d A 1 P I$ (degraded by SAP1-S1; SAP3-S3; SAP9-S9) on HMEC-1 cell viability during NET treatment (10 $\mu \mathrm{g} / \mathrm{ml})$ of HMEC-1 cells (B) was determined in the same manner. The molar ratio of A1PI/dA1PI used was calculated according to the amount of NE in NETs, estimated as was proposed by Urban et al. (2009). The possible contribution of SAP1, SAP3 and SAP9 to the observed effects was also taken into account (marked S1, S3 and S9, respectively). 

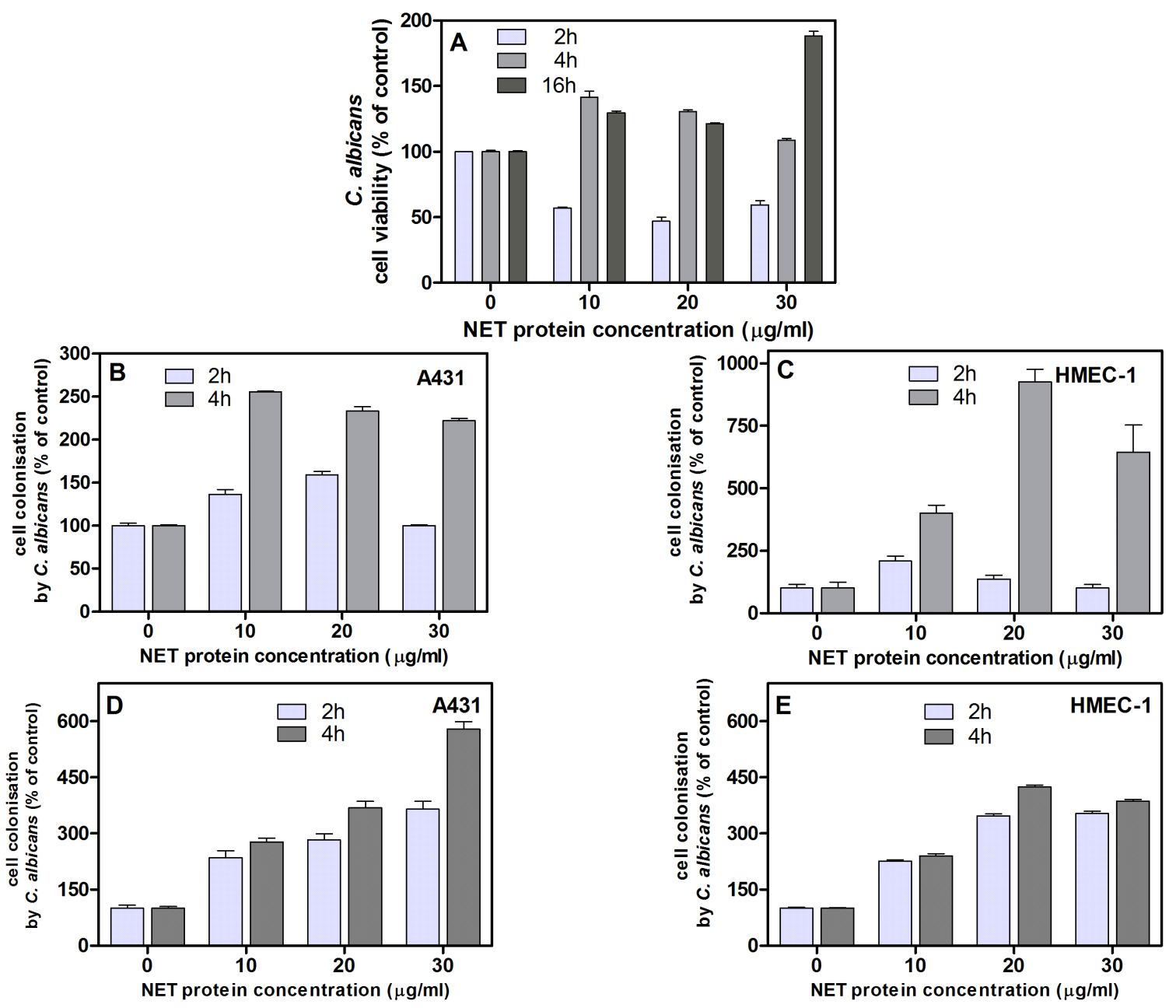

Figure 6. Influences of uncontrolled NET generation on the viability of $C$. albicans cells and the ability to colonize the NET-damaged epithelial and endothelial cells.

The yeast-like cells were treated with NET proteins $(0-30 \mu \mathrm{g} / \mathrm{ml})$ for $2-16 \mathrm{~h}$ and the fungal viability was determined by CFU measurements, in comparison to non-treated cells (A). The colonization of NET-damaged human cells by C. albicans was assayed in two models: sequential (B, C: the human cell treatment with NET, followed by colonization with C. albicans) and simultaneous (D, E: NET impaired both human and pathogen cells at the same time).

effects of destroyed neutrophils on the analyzed cells, the NET structures produced during PMA stimulation of neutrophils were first detached from the neutrophils by MNase treatment that also caused a slight fragmentation of the supporting DNA scaffold. The amount of NETs used in further experiments was determined based on their protein content. The results presented in the Fig. 5A confirmed earlier reports of destructive action of NETs on epithelial and endothelial cells, but in our models the endothelium seemed to be more susceptible to NET presence than epithelial cells.

The observed NET-generated damages to both types of cells can result from actions of many factors, constituting NETs, one of them being elastase. To verify this hypothesis the HMEC-1 monolayer was treated with NETs as was described above but at a lower protein concentration, $10 \mu \mathrm{g} / \mathrm{ml}$. The NET-dependent damages lowered the cell viability to $75 \%$. When the monolayer was treated with NETs previously incubated in the presence of increased concentrations of A1PI, the observed changes showed a gradual increase in cell viability, more or less comparable with the initial conditions, confirming that a large part of the destructive forces of NETs is constituted by elastase (Fig. 5B) whose action can be controlled and even totally blocked in NETs by A1PI. On the other hand, when A1PI was treated with SAPs known to be most potent in A1PI degradation (SAP1, SAP2, SAP9), that produced C-terminally truncated A1PI variant (dA1PI) with the concomitant loss of anti-elastase properties, the protective effect disappeared. With increasing concentrations of dA1PI the cell viability dropped to the initial destructive level. At the same time, the SAPs present at the experimental conditions, can also influence cell viability but the control results performed for pure SAPs showed only a 5-7\% contribution of SAP to this effect.

\section{Human cell destruction by NETs promotes the propagation of candidal infection}

Neutrophils use several strategies to fight against bacterial and fungal infection, including NET formation, but many microorganisms developed different mechanisms to survive. The destruction of the surrounding tissue may add to the fungal survival strategy. To verify this hypothesis, we constructed the models of mutual interactions between $C$. 
albicans cells and epithelial (A431) or endothelial (HMEC-1) cells being in contact with NETs. First, we checked the effects of isolated NETs on the viability of fungal cells (Fig. 6A). Measurements performed for a short period of contact time $(2 \mathrm{~h})$ showed about $60 \%$ decrease in fungal cell viability, but after a longer time of contact $(16 \mathrm{~h})$ the fungal cells recovered their growth, in comparison to the control conditions. Even more, some NET constituents may stimulate the fungal growth as the full neutrophil extract does (data not shown). Next, we analyzed the possible spreading of C. albicans cells over epithelial and endothelial cell monolayer, both influenced by NET treatments during different periods of time $(2-4 \mathrm{~h})$ at different NET-protein concentration $(0-30 \mu \mathrm{g} / \mathrm{ml})$. For this approach, two models were used. In the first model, the human cells were first treated with NETs for various time periods, and then NETs were removed and human cell monolayers were covered for $2 \mathrm{~h}$ by $C$. albicans cells, whose attachment and growth were further analyzed by CFU methods. In another model, human and pathogen cells were allowed to be influenced by NETs at the same time in a mutual contact. The results obtained from both models (Fig. 6B-E) clearly indicate that the damaged human cells become more susceptible to further C. albicans colonization. The longer time of NET treatment favored $C$. albicans colonization. In the light of these results, the usage of a variety of SAPs by the fungus for the deregulation of elastase control due to the SAP-dependent A1PI degradation and for possible modulation of chemotaxis serves to the superior goal, i.e. further propagation of infection. However, excessive production of NETs at the fungal infection site leads to the destruction of both fighters. Once again, the human endothelium seemed to be more sensitive for destruction and susceptible to further colonization by the fungus.

\section{DISSCUSION}

C. albicans is well adapted to changes occurring in its environment, i.e. the host tissues and cells. In the adaptation processes, $C$. albicans engages aspartic proteases to degrade tissue barriers, to inactivate host defense molecules, and to digest host proteins for nutrient supply (Naglik et al., 2003). However, SAPs also contribute to the induction of the inflammatory response of the host by stimulation of cytokine expression (Naglik et al., 2003; Schaller et al., 2005), acting directly (Pietrella et al., 2010) or in an indirect way, through a disruption of the complexes involved in maintaining the host's homeostasis. One of these interactions, important for the biochemical homeostasis in the host organism, is the protease-inhibitor complex formation between neutrophil elastase and its major regulator, A1PI.

Neutrophils, being the first immune cells arriving at the site of infection, are able to extracellularly release their granular proteins or to form NET structures, both resulting in a local eruption of neutrophil serine proteases, mainly NE, that on one hand can inactivate bacterial or fungal virulence factors (Belaaouaj et al., 1998; Tkalcevic et al., 2000), but on the other hand they are also involved in a variety of inflammatory conditions, including chronic lung diseases (chronic obstructive pulmonary disease, cystic fibrosis, acute lung injury, and acute respiratory distress syndrome) (Bergin et al., 2012). Moreover, NE induces the production of proinflammatory cytokines in the lungs, thus augmenting the inflammation (Meyer-Hoffert \& Wiedow, 2011), but also inactivates extracellular immune mediators such as immunoglobulins, complement components, and cathelicidin (Tralau et al., 2004; Stromstedt et al., 2009).
Once released, proteolytically active NE is under control of A1PI that is responsible for maintaining the balance, being of a critical importance for the protection of lung tissues (Greene et al., 2008; Reeves et al., 2010; Tuder et al., 2010). Alveolar epithelial cells are known to produce A1PI locally which may contribute to both the anti-protease defense and anti-inflammatory effects within the lung (Venembre et al., 1994). Our work shows here for the first time that such a complex between NE and A1PI can be also formed when NE is present within the NET structures.

For many bacterial infections, the NE-A1PI balance can be disturbed due to the efficient inactivation of A1PI by proteases secreted by microorganisms, resulting in serious tissue damage (Sires et al., 1994; Sponer et al., 1991). As the serpin core possesses a highly ordered structure (Elliott et al., 1998), the exposed reactivesite loop of A1PI is generally the primary target for the proteolytic attack of bacterial enzymes (Rapala-Kozik et al., 1999). Several bacterial proteases were found to operate in a close vicinity to the NE-cleavage site (M358S359) within this loop, i.e., to hydrolyze peptide bonds between residues F352 and I360 (Rapala-Kozik et al., 1999). In the current study we present for the first time that similarly, aspartic proteases of a fungal pathogen - C. albicans - can also cleave the A1PI reactive loop at the K343-G344 bond, impairing the A1PI inhibitory properties. In the selection of SAPs that are most efficient in A1PI degradation, acidic conditions were preferred. They refer to severe bacterial infections, observed in cystic fibrosis where characteristic feature of the inflammatory sites is a local acidosis, which is attributed to the increase of lactic acid production by the anaerobic, glycolytic activity of infiltrating neutrophils (Lardner, 2001; Coakley et al., 2000). Our results showed that the most efficient inactivation of A1PI was performed by SAP1, SAP2 and SAP3, proteases predominantly produced by the yeast-like forms, contributing to the pathogen dissemination. Hyphae-specific protease SAP4 also functions in the acidic environment and can be important in A1PI degradation during prolonged infections. Additionally, the surface-bound SAP9 which is expressed by both morphological forms contributes to A1PI cleavage. Thus, independently from the reversible switch between the unicellular yeast-like form and the elongated filamentous form, C. albicans is well equipped with the A1PI-degrading power. The action of SAP9 can be of a special importance if the fungus is locally arrested in NET structures. Our data are consistent with previous observations that $C$. albicans mutants lacking either SAP1 or $S A P 2$ genes caused a lesser tissue damage in infection models and had a significantly reduced potential to stimulate cytokine expression. In contrast, mutants lacking SAP4 to SAPG induced similar levels of cytokines to those in the wild-type strain (Schaller et al., 2003).

The same data had shown that plasma A1PI binds to circulating neutrophils and is localized to the outer surface of the cell membrane which may facilitate the ability of A1PI to regulate key neutrophil inflammatory responses including cell chemotaxis (Bergin et al., 2010). By forming the complex with IL-8, A1PI inhibits CXCR1 engagement, with a negative impact on the downstream CXCR1 signaling events. Our present results show that the degradation of A1PI by fungal proteases affects not only the interaction with elastase but also the complex formation between A1PI and IL-8. This chemokine interacts with glycosylated part of A1PI molecule via charge complementation (Bergin et al., 2010; Reeves et al., 2010). Although the SAP-truncated A1PI retains all 
the binding sites for IL- 8 , the interaction is weaker by ca. 50\%, as compared to native A1PI molecule. This may be related to possible changes in A1PI conformation that can occur during proteolysis of reactive site loop, limiting access to IL-8 binding sites (Knäuper et al., 1990).

Our results correspond to the findings of Pietrella et al. (2010) who demonstrated a strong ability of SAP1, SAP2 and SAP6 to induce inflammatory cytokines, and are consistent with a low capacity to induce inflammation found in null mutants lacking either SAP1 or SAP2 (Schaller et al., 2005). Such uncontrolled local accumulation of IL-8 can be involved in the recruitment of neutrophils to the site of infection and is observed under conditions of persistent neutrophilic airway inflammation (Hartl et al., 2007). For example, during the initial stages of acute lung injury and acute respiratory distress syndrome, a massive accumulation of neutrophils in the vasculature of the lung was also identified (Cheng et al., 2013).

The migration of neutrophils to sites of infection is beneficial for the host because of their ability to kill pathogens. However, the presence of neutrophils at the infection foci may also be deleterious when an excessive, uncontrolled amount of $\mathrm{NE}$ is released into the extracellular medium, leading to lung matrix degradation. Pathologic effects of NE are also associated with microvascular injury, causing endothelial damage and increased capillary permeability that may enhance the translocation of microorganisms across the endothelial cell barrier and initiate bacteremia (Moraes et al., 2003). In epithelial and endothelial cell models, used in the present study, we also found that NET-associated NE partially influences the viability of both cell types. The effect is most pronounced when NE activity is no longer controlled by SAP-truncated A1PI. But at the same moment, a destruction of pathogen also occurred. Such effects raise a question if the local imbalance in the host protein homeostasis is really cost-effective for $C$. albicans cells, where parts of the population could be killed during deregulation of the host homeostasis. However, our models of NET-dependent impairment of epithelial and endothelial cells clearly indicated that the cells presented a surface more accessible for C. albicans colonization. Even the partial destruction of $C$. albicans cells in this situation cannot influence the total population of pathogen cells. Although the observation on a short time scale demonstrated drastic fungal killing effects, very often shown in published reports, during longer time of colonization, the remaining and still alive fungal cells can restore the whole population or even stimulate its growth by a yet unidentified stimulator, liberated during neutrophil breakdown, as was also noted by Urban et al. (2006).

Moreover, C. albicans is often associated with the polymicrobial community that is more resistant to any treatment, as it was shown in pneumonia and cystic fibrosis, where C. albicans interacts with typical pneumonia pathogens, such as Pseudomonas aeruginosa (Mear et al., 2013; Ader et al., 2011). It is probable that in such situations, especially in pulmonary fungal infections which have been systematically studied in recent years (Chotirmall \& MacElvaney, 2014; Roux et al., 2013; Wahab et al., 2014), the deregulation of well-balanced homeostatic proteinprotein complexes of the host is more profitable for maintaining the pathogen community.

Taken together, the results obtained in the present study reveal that $C$. albicans SAPs are able to disturb A1PI-NE complex formation, thus influencing epithelial and endothelial cell colonization and adding another pro- cess of cytokine enhancement to the virulence attributes of this fungal pathogen.

\section{Competing interests}

The authors declare that they have no competing interests.

\section{Acknowledgements}

This work was supported in part by the National Science Centre, Poland (grant No. 2012/05/B/NZ1/00003 awarded to MRK). The Faculty of Biochemistry, Biophysics and Biotechnology of the Jagiellonian University in Krakow is a beneficiary of structural funds from the European Union (grant no. POIG.02.01.00-12-064/08, "Molecular Biotechnology for Health") and a partner of the Leading National Research Center (KNOW) supported by the Ministry of Science and Higher Education, Poland.

\section{REFERENCES}

Ader F, Jawhara S, Nseir S (2011) Short term Candida albicans colonization reduces Pseudomonas aeruginosa-related lung injury and bacterial burden in a murine model. Crit Care 15: R150. http://doi. org/10.1186/cc10276.

Aoki W (2011) Comprehensive characterization of secreted aspartic proteases encoded by a virulence gene family in Candida albicans. J Biochem 150: 431-438. http://doi.org/10.1093/jb/mvr073.

Bakare N, Rickerts V, Bargon J, Just-Nübling G (2003) Prevalence of Aspergillus fumigatus and other fungal species in the sputum of adult patients with cystic fibrosis. Mycoses 46: 19-23. http://doi.org/10.10 46/j.1439-0507.2003.00830.

Belaaouaj A, McCarthy R, Baumann M, Gao Z, Ley TJ, Abraham SN (1998) Mice lacking neutrophil elastase reveal impaired host defense against gram negative bacterial sepsis. Nat Med 4: 615-618. http:// doi.org/10.1038/nm0598-615.

Bergin DA, Reeves EP, Meleady P, Henry M, McElvaney OJ, Carroll TP, McElvaney NG (2010) $\alpha-1$ Antitrypsin regulates human neutrophil chemotaxis induced by soluble immune complexes and IL-8. J Clint Invest 120: 4236-4250. http://doi.org/10.1172/JCI41196.

Bergin DA, Hurley K, McElvaney NG, Reeves EP (2012) Alpha-1 antitrypsin: a potent anti-inflammatory and potential novel therapeutic agent. Arch Immunol Ther Exp 60: 81-97. http://doi.org/10.1007/ s00005-012-0162-5.

Blum H, Beier H, Gross HJ (1987) Improved silver staining of plant proteins, RNA and DNA in polyacrylamide gels. Electrophoresis 8: 93-99.

Buff SJ, McLelland R, Gallis HA, Matthay R, Putman CE (1982) Candida albicans pneumonia: Radiographic appearance. Am J Roentgenol 138: $645-648$.

Calderone R, Fonzi W (2001) Virulence factors of Candida albicans. Trends Microbiol 9: 327-35. http://doi.org/10.1016/S0966842X(01)02094-7.

Cheng OZ, Palaniyar N (2013) NET balancing: A problem in inflammatory lung diseases. Front Immunol 4: 1-13. http://doi. org/10.3389/fimmu.2013.00001.

Chotirmall SH, McElvaney NG (2014) Fungi in the cystic fibrosis lung: bystanders or pathogens? Int J Biochem Cell Biol 52: 161-173. http:// doi.org/10.1016/j.biocel.2014.03.001.

Coakley RJ, Taggart C, Canny G, Greally P, O’Neill SJ, McElvaney NG (2001) Altered intracellular $\mathrm{pH}$ regulation in neutrophils from patients with cystic fibrosis. Am J Physiol Lung Cell Mol Physiol 279: L66-L74.

Elliott PR, Bilton D, Lomas DA (1998) Lung polymers in Z a1-antitrypsin deficiency-related emphysema. Am J Respir Cell Mol Biol 18: 670-674. http://doi.org/10.1165/ajrcmb.18.5.3065.

Greene C, Taggart C, Lowe G, Gallagher P, McElvaney N, O’Neill S (2003) Local impairment of anti-neutrophil elastase capacity in community-acquired pneumonia. J Infect Dis 188: 769-776. http:// doi.org/10.1086/377238.

Greene C, Miller S D, Carroll T, McLean C, O’Mahony M, Lawless MW, O’Neill SJ, Taggart CC, McElvaney NG (2008) Alpha-1antitrypsin deficiency: a conformational disease associated with lung and liver manifestations. I Inherit Metab Dis 31: 21-34. http://doi. org/10.1007/s10545-007-0748-y.

Hartl D, Latzin P, Hordijk P, Marcos V, Rudolph C, Woischnik M, Krauss-Etschmann S, Koller B, Reinhardt D, Roscher AA (2007) Cleavage of CXCR1 on neutrophils disables bacterial killing in 
cystic fibrosis lung disease. Nat Med 13: 1423-1430. http://doi. org/10.1038/nm1690.

Hube B, Sanglard D, Odds FC, Hess D, Monod M, Schäfer W, Gow NR (1997) Disruption of each of the secreted aspartyl proteinase genes SAP1, SAP2, and SAP3 of Candida albicans attenuates virulence. Infect Immun 65: 3529-3538.

Hube B, Naglik J (2001) Candida albicans proteinases: resolving the mystery of a gene family. Microbiology 147: 1997-2005. http://doi. org/10.1099/00221287-147-8-1997.

Kaminishi H, Miyaguchi H, Tamaki T (1995) Degradation of humoral host defense by Candida albicans proteinase. Infect Immun 63: 984-988.

Knäuper V, Reinke H, Tschesche H (1990) Inactivation of human plasma alpha 1-proteinase inhibitor by human PMN leucocyte collagenase. FEBS Letters 263: 355-357. http://doi.org/10.1016/00145793(90)81412-H.

Kozik A, Gogol M, Bochenska O, Karkowska-Kuleta J, Wolak N, Kamysz W, Aoki W, Ueda M, Faussner A, Rapala-Kozik M (2015) Kinin release from human kininogen by 10 aspartic proteases produced by pathogenic yeast Candida albicans. BMC Microbiology 15: 60 . http://doi.org/10.1186/s12866-015-0394-8.

Lardner A (2001) The effects of extracellular $\mathrm{pH}$ on immune function. J Leukoc Biol 69: 522-530.

Limper AH (2010) The changing spectrum of fungal infections in pulmonary and critical care practice: clinical approach to diagnosis. Proc Am Thorac Soc 7: 163-168. http://doi.org/10.1513/pats.200906049AL.

Méar JB, Kipnis E, Faure E, Dessein R, Schurtz G, Faure K, Guery B (2013) Candida albicans and Pseudomonas aeruginosa interactions: more than an opportunistic criminal association? Med Mal Infect 43: 146151. http://doi.org/10.1016/j.medmal.2013.02.005.

Mech F, Wilson D, Lehnert T, Hube B, Thilo Figge M (2013) Epithelial invasion outcompetes hypha development during Candida albicans infection as revealed by an image-based systems biology approach. Cytometry A 85: 126-139. http://doi.org/10.1002/cyto.a.22418.

Meyer-Hoffert U, Wiedow O (2011) Neutrophil serine proteases: mediators of innate immune responses. Curr Opin Hematol 18: 19-24. http://doi.org/10.1097/MOH.0b013e328341 $15 \mathrm{~d} 1$.

Moraes TJ, Chow CW, Downey GP (2003) Proteases and lung injury. Crit Care Med 31: S189-S194.

Naglik JR, Challacombe SJ, Hube B (2003) Candida albicans secreted aspartyl proteinases in virulence and pathogenesis. Microbiology Mol Biol Rev 67: 400-428. http://doi.org/10.1128/MMBR.67.3.400.

Naglik JR, Moyes D, Makwana J, Kanzaria P, Tsichlaki E, Weindl G, Hube B (2008) Quantitative expression of the Candida albicans secreted aspartyl proteinase gene family in human oral and vaginal candidiasis. Microbiology 154: 3266-3280. http://doi.org/10.1099/ mic.0.2008/022293-0.

Nikawa H, Egusa H, Makihira S, Okamoto T, Kurihara H, Shiba H, Hamada T (2006) An in vitro evaluation of the adhesion of Candida species to oral and lung tissue cells. Mycoses 49: 14-17. http://doi. org/10.1111/j.1439-0507.2005.01176.x.

Papayannopoulos V, Staab D, Zychlinsky A (2011) Neutrophil elastase enhances sputum solubilization in cystic fibrosis patients receiving dnase therapy. PLoS One 6: 1-7. http://doi.org/10.1371/journal. pone.0028526.

Pietrella D, Rachini A, Pandey N, Schild L, Netea M, Bistoni F, Vecchiarelli A (2010) The inflammatory response induced by aspartic proteases of Candida albicans is independent of proteolytic activity. Infect Immun, 78: 4754-4762. http://doi.org/10.1128/IAI.00789-10.

Rapala-Kozik M, Bochenska O, Zawrotniak M, Wolak N, Trebacz G, Gogol M, Ostrowska D, Aoki W, Ueda M, Kozik A (2015) Inactivation of the antifungal and immunomodulatory properties of human cathelicidin LL-37 by aspartic proteases produced by the pathogenic yeast Candida albicans. Infect Immun 83: 2518-2530. http://doi. org/10.1128/IAI.00023-15.

Rapala-Kozik M, Potempa J, Nelson D, Kozik A, Travis J (1999) Comparative cleavage sites within the reactive-site loop of native and oxidized $\alpha 1$-proteinase inhibitor by selected bacterial proteinases. Biol Chem 380: 1211-1216. http://doi.org/10.1515/BC.1999.153.

Reeves EP, Williamson M, Byrne B, Bergin D, Smith SGJ, Greally P, McElvaney NG (2010) IL-8 dictates glycosaminoglycan binding and stability of IL-18 in cystic fibrosis. J Immun 184: 1642-1652. http:// doi.org/10.4049/jimmunol.0902605.

Rinehart A R, Mallya S, Simon S R (1993) Human $\alpha$ 1-proteinase inhibitor binds to extracellular matrix in vitro. Am J Respir Cell Mol Biol 9: 666-679. http://doi.org/10.1165/ajrcmb/9.6.666.
Roux D, Gaudry S, Khoy-Ear L, Aloulou M, Phillips-Houlbracq M, Bex J, Skurnik D, Denamur E, Monteiro RC, Dreyfuss D, Ricard JD (2013) Airway fungal colonization compromises the immune system allowing bacterial pneumonia to prevail Crit Care Med 41: 191-199. http://doi.org/10.1097/CCM.0b013e31828a25d6.

Saffarzadeh M, Juenemann C, Queisser MA, Lochnit G, Barreto G, Galuska SP (2012) Neutrophil extracellular traps directly induce epithelial and endothelial cell death: a predominant role of histones. PLoS One 7: e32366. http://doi.org/10.1371/journal.pone.0032366.

Santos ALS, Braga-Silva L (2013) Aspartic protease inhibitors: effective drugs against the human fungal pathogen Candida albicans. Mini-Rev Med Chem 13: 155-162. http://dx.doi.org/10.2174/13895575113070 10155.

Schaller M, Schäfer W, Korting HC, Hube B (1998) Differential expression of secreted aspartyl proteinases in a model of human oral candidosis and in patient samples from the oral cavity. Mol Microbiol 29: 605-615. http://doi.org/10.1046/j.1365-2958.1998.00957.x.

Schaller M, Bein H C, Korting S, Baur G, Hamm M, Monod S, Beinhauer, Hube B (2003) The secreted aspartyl proteinases Sap1 and Sap2 cause tissue damage in an in vitro model of vaginal candidiasis based on reconstituted human vaginal epithelium. Infect Immun 71: 3227-3234. http://doi.org/10.1128/IAI.71.6.3227-3234.2003.

Schaller M, Korting HC, Borelli C, Hamm G, Hube B (2005) Candida albicans-secreted aspartic proteinases modify the epithelial cytokine response in an in vitro model of vaginal candidiasis. Infect Immun $\mathbf{7 3}$ : 2758-2765. http://doi.org/10.1128/IAI.73.5.2758-2765.2005.

Sponer M, Nick HP, Schnebli HP (1991) Different susceptibility of elastase inhibitors to inactivation by proteinases from Staphylococcus aureus and Pseudomonas aeruginosa. Biol Chem 372: 963-970.

Stromstedt AA, Pasupuleti M, Schmidtchen A, Malmsten M (2009) Evaluation of strategies for improving proteolytic resistance of antimicrobial peptides by using variants of EFK17, an internal segment of LL-37. Antimicrob Agents Chemother 53: 593-602. http://doi. org/10.1128/AAC.00477-08.

Suter S, Chevallier I (1991) Proteolytic inactivation of alpha-1-proteinase inhibitor in infected bronchial secretions from patients with cystic fibrosis. Eur Res J 4: 40-49.

Tagami T, Tosa R, Omura M (2014) Effect of a selective neutrophil elastase inhibitor on mortality and ventilator-free days in patients with increased extravascular lung water: a post hoc analysis of the PiCCO Pulmonary Edema Study. J Inten Care 2: 67. http://doi. org/10.1186/s40560-014-0067-y.

Taggart C, Cervantes-Laurean D, Kim G, McElvaney NG, Wehr N, Moss J, Levine RL (2000) Oxidation of either methionine 351 or methionine 358 in alpha-1-antitrypsin causes loss of anti-neutrophil elastase activity. J Biol Chem 275: 27258-27265. http://doi. org/10.1074/jbc.M004850200.

Takemasa A, Ishi Y, Fukuda T (2012) A neutrophil elastase inhibitor prevents bleomycin-induced pulmonary fibrosis in mice. Europ Resp J 40: 1475-1482. http://doi.org/10.1183/09031936.00127011.

Tralau T, Meyer-Hoffert U, Schroder JM, Wiedow O (2004) Human leukocyte elastase and cathepsin $G$ are specific inhibitors of $C 5 \mathrm{a}$ dependent neutrophil enzyme release and chemotaxis. Exp Dermatol 13: 316-25. http://doi/10.1111/j.0906-6705.2004.00145.x.

Tuder RM, Janciauskiene SM, Petrache I (2010) Lung Disease Associated with $\alpha_{1}$-Antitrypsin Deficiency. Proc Am Thorac Soc 7: 381-386. http://doi.org/10.1513/pats.201002-020AW.

Urban CF, Reichard U, Brinkmann V, Zychlinsky A (2006) Neutrophil extracellular traps capture and kill Candida albicans yeast and hyphal forms. Cell Microbiol 8: 668-676. http://doi.org/10.1111/ j.1462-5822.2005.00659.x.

Urban CF, Ermert D, Schmid M, Abu-Abed U, Goosmann C, Nacken W, Zychlinsky A (2009) Neutrophil extracellular traps contain calprotectin, a cytosolic protein complex involved in host defense against Candida albicans. PLoS Pathogens 5: e1000639. http://doi. org/10.1371/journal.ppat.1000639.

Wahab AA, Taj-Aldeen SJ, Kolecka A, ElGindi M, Finkel JS, Boekhout T (2014). High prevalence of Candida dubliniensis in lower respiratory tract secretions from cystic fibrosis patients may be related to increased adherence properties. Int J Infect Dis 24: 14-19. http:// doi.org/10.1016/j.ijid.2014.03.1380.

Venembre P, Boutten A, Seta N, Dehoux MS, Crestani B, Aubier M, Durand G (1994) Secretion of alpha 1-antitrypsin by alveolar epithelial cells. FEBS Lett 346: 171-174. 